\title{
ALGUNAS IDEAS SOBRE LA CONSTITUCIÓN DEL CUERPO EN LA EXPERIENCIA DE VIDEOJUEGO ${ }^{1}$
}

\author{
SOME IDEAS ABOUT THE CONSTITUTION OF THE \\ BODY IN THE VIDEOGAME EXPERIENCE
}

ALGUMAS IDEIAS SOBRE A CONSTITUIÇÃO DO CORPO NA EXPERIÊNCIA DO VIDEOJOGO

Zairo Pineda Roa ${ }^{2}$

\section{Resumen}

\begin{abstract}
Este escrito intenta relacionar el tema del videojuego con el del cuerpo y la formación, desde la síntesis pasiva planteada por la fenomenología de Husserl. A partir de aspectos como el cuerpo, el entorno circundante y el tiempo se desarrolla la reflexión acerca del videojuego donde a través de un personaje-avatar tiene lugar la experiencia, de acuerdo con los hilos narrativos propuestos por el juego. El avatar problematiza la relación con su jugador, es decir quien está frente a la pantalla, así como con el mundo narrativo planteado por el juego. En este sentido, para quien se encuentra frente a la pantalla, se abren posibilidades de constitución subjetiva en cuanto se ha desdoblado y se moviliza por los pixeles de la pantalla. Asimismo, la formación entra a escena en cuanto constituye un elemento para pensar la experiencia de juego en razón de quien o quienes lo juegan.
\end{abstract}

Palabras clave: fenomenología; síntesis pasiva; constitución del cuerpo; videojuego y formación

\section{Abstract}

This article of reflection tries to relate the theme of the video game with that of the body and the formation, from the passive synthesis posed by the phenomenology of Husserl. From aspects such as the body, the surrounding environment and time, the reflection about the video game is developed, where through an avatar-character the experience takes place, according to the narrative threads proposed by the game. The avatar problematizes the relationship with his player, that is, who is in front of the screen, as well as with the narrative world posed by the game. In this sense, for those who are in front of the screen, possibilities of subjective constitution are opened as soon as it has unfolded and is mobilized by the pixels of the screen. Also, training enters the scene as it is an element to think about the game experience because of who plays or who play it.

Keywords: phenomenology; passive synthesis; constitution of the body; video game; training

1 Este escrito hace parte del seminario Educación y Pedagogía, titulado: Pasividad y Formación en Ideas II de Edmund Husserl.

2 Magíster en Desarrollo Educativo y Social. Especialista en Tecnologías de la Información Aplicadas a la Educación. Especialista en Pedagogía. Licenciado en Diseño Tecnológico. Estudiante de Doctorado Interinstitucional en Educación. Universidad Pedagógica Nacional, Universidad Distrital Francisco José de Caldas, Universidad del Valle. Docente de Tecnología e Informática en el IED José Martí. Secretaría de Educación de Bogotá. Colombia. Correo electrónico: zairo97@gmail.com 


\section{Resumo}

Este artigo de reflexão tenta relacionar o tema do videogame com o do corpo e da formação, a partir da síntese passiva proposta pela fenomenologia de Husserl. A partir de aspectos como o corpo, o meio envolvente e o tempo, desenvolve-se a reflexão sobre o videojogo, onde através de um personagem de avatar se realiza a experiência, de acordo com os fios narrativos propostos pelo jogo. 0 avatar problematiza a relação com o jogador, ou seja, quem está na frente da tela, bem como com o mundo narrativo proposto pelo jogo. Nesse sentido, para aqueles que estão na frente da tela, as possibilidades de constituição subjetiva são abertas assim que se desdobram e são mobilizadas pelos pixels da tela. Além disso, o treinamento entra em cena, pois é um elemento para pensar sobre a experiência do jogo por causa de quem joga ou quem jogam.

Palavras-chave: fenomenologia; síntese passiva; constituição do corpo; videogame, formação

Fecha de recepción: 1 de septiembre de 2016

Fecha de aprobación: 4 de octubre de 2018

Para citar este artículo

Pineda, Z. (2018). Algunas ideas sobre la constitución del cuerpo en la experiencia de videojuego. Lúdica Pedagógica, 27, x-xx. 
Al lado de estos cursos cinestésicos libres se presentan otros que están caracterizados en lugar de como algo hecho a mí, como transcursos pasivos en los que la espontaneidad no tiene ninguna participación. En este caso tenemos a la vez un experimentar el proceso / del movimiento corporal y una dación del proceso con el carácter anímico del padecer; no entendido en el sentido del dolor, de una repugnancia, sino simplemente, en el sentido de mi mano es movida, mi pie es empujado arrimado, etc.

Husserl (2005, p. 199)

\section{INTRODUCCIÓN}

Desde la fenomenología de Husserl, es posible destacar dos grandes formas, una relacionada con lo activo, la intención y el pensamiento objetivo o científico, otra desde la síntesis pasiva que tiene lugar en términos de la experiencia, el cuerpo, el pensamiento precientífico. Aquí nos interesa orientar la reflexión desde la segunda, esto es, desde síntesis pasiva. La pasividad constituye un momento y un espacio en el videojuego, donde el cuerpo hace una puesta en escena no intencional o no racionalmente programada y sí, una manera de estar en una vivencia donde múltiples saberes - a manera de intuiciones - tienen lugar, de modo automático, pero que no son objeto de estudio problemático desde la formación. En tal vivencia:

Mientras que el mismo objeto puede darse a diferentes personas, la vivencia de cada persona es diferente. Mientras que Juan y María pueden ambos percibir el mismo limón, cada uno tiene su propia vivencia de él. Precisamente, este tipo de donación en primera persona convierte la vivencia en subjetiva. (Escudero, 2013, pp. 37 38).

Por tanto, la percepción del objeto es común a varios sujetos, es compartido intersubjetivamente, mientras su vivencia ocurre de manera individual, en primera persona, es subjetiva. En el videojuego, como objeto tecnológico, desde su narración es posible ser jugado, experimentado como una vivencia y también en la forma de juego multijugador la percepción se comparte; el cruce entre estas dos facetas problematiza la constitución subjetiva e intersubjetiva en cuanto la experiencia de juego. Esto en relación con la síntesis pasiva, en la manera en que en "mi vida cotidiana estoy, por lo general, absorto en mis quehaceres y preocupado por mis proyectos, apenas prestando atención a mis vivencias como tales, esto es, la autoconciencia prerreflexiva" (Escudero, 2013, p. 39) Un jugador puede estar sin más con su juego, apenas videojugando.

Así, algunas inquietudes que motivan la relación entren síntesis pasiva y videojuego tienen que ver con: ¿qué formas de constitución de subjetividad y de formación tienen lugar según la experiencia en el videojuego? Y, entonces, ¿qué papel tiene el cuerpo en relación con la constitución subjetiva y la formación misma?

\section{VIDEOJUEGO, CUERPO Y FORMACIÓN DESDE LA SÍNTESIS PASIVA}

Habitualmente en la relación del sujeto con el conocimiento y la realidad misma o los objetos concretos, se resalta el hacer y pensar intencionado y espontáneo conforme a unos sentidos previos, racionalmente objetivos y medibles, que llevan a formar sujetos competentes. Se ha normalizado la regla, el proceder correcto racional, quedando por fuera posibilidades no racionales en los que elementos como el cuerpo y la experiencia constituyen zonas boscosas, extrañamente cartografiables, que hacen de la intuición un elemento performativo en la configuración de la subjetividad desde la conjunción entre el jugador y el videojuego, entre otras múltiples realidades u objetos. Se tiene como tesis que la constitución del cuerpo tiene lugar en la experiencia de juego.

En este orden, se bordea una región donde el pensamiento intuitivo y los sujetos vistos, en términos de Dreyfus y Dreyfus (2000) como, ejecutor diestro (proficient performer) y ejecutor perito (expert performer), constituyen formas de relación con el mundo, de experimentarlo. En síntesis pasiva nos centramos en el ejecutor perito, quien:

[...] gracias a un vasto repertorio de discriminaciones situacionales, ve cómo lograr su meta. La habilidad de hacer discriminaciones más sutiles y refinadas [...] Esto es, con suficiente experiencia en una variedad de situaciones, todas vistas desde la misma perspectiva pero requiriendo decisiones tácticas diferentes, el cerebro del ejecutor perito (expert performer) descompone gradualmente esta clase de situaciones en subclases, cada una de las 
cuales comparten la misma acción. Esto posibilita la respuesta inmediata, situacional e intuitiva, que caracteriza a la pericia (expertise). (Dreyfus y Dreyfus, 2000, pp. 6-7).

Entonces, el perito hace de su experiencia una escenificación de su saber, de su intuición, la cual ha constituido desde un ensayar que le permite moverse, según las cada vez más sofisticadas formas de captar, creando un repertorio de posibilidades en las que, ante una particular situación, pone en marcha singulares actuaciones y decisiones, lo cual configura su experticia en la materia en cuestión: el videojuego. El experto ha logrado tal actuación y saber gracias a una percepción que matiza el detalle y lo hace parte de su constitución; esta percepción se actualiza así, "la potencialidad o inactualidad se refiere exclusivamente a la posibilidad de volver a percibir en el primer plano objetos que han sido captados con anterioridad" (Rabanaque, 1993, p. 12), esta renovada percepción del objeto permite una actualización singular a la situación presentada. En este sentido, la formación ha tenido lugar desde un ámbito de lo activo frente a lo pasivo, donde:

naturalmente hay que distinguir la constitución del mundo sensible y la constitución del mundo "verdadero" del mundo para el sujeto científico, que se dedica al pensar y en general al investigar espontáneo, "libre". O sea: si vivimos pasiva, animalmente, "en el mundo" y en trato mutuo con nuestros iguales, todos los cuales son tan normales como nosotros, entonces se constituye un mundo de experiencia que nos es común. (Husserl, 2005, p. 122).

Así, pensar al otro, en su formación, ha sido principalmente desde procesos activos, del hacer según criterios previamente preescritos que destacan una forma de pensar el mundo, la realidad, mediada por la intención, lo científico, con formas de evaluación que reafirman la racionalidad, la actividad según objetivos; esto es importante, no obstante, esa pasividad en la que no pienso, la formación trata de hacerla a un lado, para lo cual pide pensar, el "muévase", el "está dormido" ¡despierte!. Se han dejado de lado saberes relacionados con un pensamiento pasivo que vinculan al sujeto con el conocimiento desde una perspectiva experiencial, subjetiva, contextual, una experiencia donde la inmersión a través del cuerpo constituye la primera aproximación con el conocimiento.
En este orden de ideas, "teniendo en cuenta el impacto de la experiencia en la manera de hacer sentido del mundo, la síntesis pasiva ayuda a entender que hay otro factor, otro nivel de valor social, [...] el grado en que puede ayudar a dar forma a la imaginación social en formas deseables" (De Roo, 2013, pp. 91, 92). El espacio de experiencia perceptiva en que mi relación con el mundo, con el otro desarrolla una constitución automática dada por la pasividad, conlleva a poner un acento singular en la forma como, desde la experiencia, se actualiza un ser en situación, su potencia en cuanto ser constituido y en constitución que desde el cuerpo y sus posibilidades de actuación hace latente formas alternativas de imaginar, lo otro como videojuego, el otro. En este orden de ideas, la pasividad:

[...] no es la recepción por parte nuestra de una realidad ajena o la acción causal del exterior en nosotros: es un investir, un ser en situación, ante el cual no existimos, que perpetuamente recomenzamos y que es constitutivo de nosotros mismos. Una espontaneidad "adquirida" de una vez por todas "se perpetua en el ser en virtud de lo adquirido". (Ponty, 1993, p. 435).

Tal investir le confiere al sujeto un saber que le permite transitar el mundo con una intuición esclarecedora que, aunque preconsciente, constituye su primer anclaje de desenvolvimiento en una situación. Así, en "la adquisición de conocimientos originales, la percepción se hace también permanente, su posesión se hace duradera, es una posesión que está a nuestra disposición en cualquier momento" (Husserl, 2001, p. 47. Texto original en inglés). Saberes que se van acumulando, enriqueciendo en razón de nuevas aprehensiones o percepciones del objeto. Husserl (2005) afirma que, "en la intuición de algo real radica, [...] que en su aprehensión deje abiertas otras dependencias reales que todavía no pertenecen determinadamente (así sea determinadamente según la naturaleza particular) a la composición de la aprehensión ejecutada" (pp. 195, 196). En consecuencia, desde el mundo del videojuego, su aprehensión transcurre a manera de momentos, situaciones de experiencia que poco a poco le van dando mayor habilidad en su interacción con el juego, no se inicia gamer, se llega a gamer en virtud de repetidas jugadas y ensayos, la pericia está dada por una constante aprehensión de nuevas facetas perceptivas del juego mismo. 
Ahora bien, las "determinaciones se relacionan con una normalidad de la experiencia que puede cambiar de un medio circundante a otro" (Husserl, 1980, p. 213), esto lleva a que constituirse en gamer suceda en parcialidades y normalidades referidas al contexto de experiencia de juego, las cuales van configurando un saber del objeto abierto a nuevas actuaciones; el cambio de medio circundante en el contexto del videojuego, se normaliza en cuanto más se práctica, se habitúa el jugador generando la pericia, pero en cuanto se cambia de juego, al lado de las determinaciones (destrezas que se encuentran latentes o sedimentadas), es necesario aprender nuevas normas, la experiencia anterior de jugar permanece en el trasfondo. Es necesario volver a aprender, volver a habituarse a las normalidades y pasividades del nuevo entorno de juego. Con la experiencia puesta ahora en otros juegos la pericia puede estar distribuida en los diferentes entornos de videojuego, resultando un videojuego como el de mayor experticia en cuanto mayor sea el grado de interacción con él. Así pues:

[...] en nuevas aprehensiones y ampliaciones de la antigua, a nuevas circunstancias como algo dependiente de ellas, con lo cual se constituyen propiedades reales del mismo objeto real. El sentido de la aprehensión ampliada prescribe entonces la especie que la marcha de la experiencia tiene que verificar y determinar con más precisión. Con la determinación más precisa, la aprehensión misma se configura entonces necesariamente de manera más plena. (Husserl, 2005, pp. 195, 196).

En este orden de ideas, el manejo intuitivo de un videojuego, de los controles, de la interfaz, el avatar y su movilidad por la narración, pasa por un constante perfeccionamiento que le confiere al sujeto cada vez mayor experticia. Dreyfus comenta que:

el perito normalmente no calcula. No resuelve problemas. Ni siquiera piensa. Simplemente hace lo que normalmente funciona y, por supuesto, funciona normalmente [...] Ningún número de reglas o hechos puede capturar el conocimiento que tiene un perito cuando ha almacenado su experiencia de resultados efectivos de decenas de miles de situaciones. (Dreyfus y Dreyfus 1983, pp. 7, 8).

En este sentido, la experiencia cotidiana, persistente con los objetos del mundo circundante, como el videojuego, le preservan al jugador un acumulado de saberes que le permiten orientarse intuitivamente, construir una relación en un sentido de perito, de actuación performativa según las diferentes situaciones y objetos del juego. Así, el mundo aparentemente sin orden, sin nombre, adquiere sentido en cuanto estos objetos son relacionados de manera experiencial, como lo comenta Husserl a partir del concepto de lo típico, cuando afirma:

los objetos que nos encontramos cotidianamente, estos nos muestran en su particularidad un horizonte de tipicidad. Los tipos extraesenciales o precientíficos, según Husserl, responden a este tipo de experiencia por la cual aferramos una unidad elemental entre objetos, como puede ser la que nos lleva a pensar en las ballenas como un pez vinculado en todos sus aspectos al mundo marino. (De los reyes Reyes, 2013, pp. 86-87).

Con esto, es posible afirmar que la constitución de sentido desde la síntesis pasiva esté acompañada de la constitución de relaciones típicas entre los objetos de acuerdo con el entorno en que se inscriben, con lo cual el mundo se hace nombrable, decible intuitivamente, como el caso que muestra Turkle (1997),

"Me estoy comiendo a tu orgot", nos dice el juego. Le pregunto a Tim: “¿Qué es un orgot?”. No lo sabe. "Lo ignoro", dice. "No necesitas saber con qué tipo de material estás jugando." [...] "Ignoro la palabra, pero creo que es una especie de organismo. Nunca había leído esto, pero a partir del juego, diría que es eso".

La cuestión del orgot no se quedó aquí: "Tu flamante orgot ha derivado en otra especie", nos informa el juego. (p. 89)

Así, es posible diferenciar y referenciar objetos y entornos de un juego como Halo (relacionado con la guerra), a objetos, acciones y situaciones de otro juego como FIFA (juego de fútbol) e ir construyendo una experticia intuitiva en cada juego. Esto es posible en cuanto el hombre, "se encuentra como referido realmente a su mundo circundante cósico y espiritual. [...] su realidad como persona consiste precisamente en tener propiedades reales (como propiedades personales) que poseen referencias reguladas a este mundo circundante" (Husserl, 2005, p. 180). Estas referencias inician desde un elemento común a todos: el cuerpo. 
En este sentido, "en un caso el 'mundo circundante' ofrece el sistema de circunstancias reales; en el otro caso, el mero cuerpo y el nexo de conciencia transcurrido" (Husserl, 2005, p. 180). Por tanto, para pensar la construcción pasiva del videojuego, de su realidad, el mundo circundante y el cuerpo constituyen las dos primeras referencias para la construcción del sentido. Así, "la conciencia total de un hombre está enlazada en cierta manera con su cuerpo mediante su soporte hylético ${ }^{3}$; pero está claro que las vivencias intencionales mismas ya no están directa y propiamente localizadas, ni forman ya un estrato en el cuerpo" (Husserl, 2005, p. 193). En consecuencia, la noción de pasividad configura un mundo desde las sensaciones propias de la materialidad del cuerpo y su estar en el mundo, desde la multiplicidad de posibilidades que con sus sensaciones le son propias o inherentes a cada sujeto o a grupos de ellos. Desde el cuerpo, como principal soporte de la experiencia, estas sensaciones no solo se encuentran localizadas, sino que hacen parte de un sistema, así, "en ninguna sensación corporal se capta la mera sensación, sino que esta es aprehendida como inherente a un sistema" (Husserl, 2005, p. 194). Un sistema donde cada nueva aprehensión entra a ser parte del acumulado experiencial, que tiene como eje el cuerpo material.

Este captar convoca una corporalidad que se ubica en un entorno y circunstancias y así lo percibe de acuerdo con un orden posicional, del cuerpo, lo que conlleva a particulares formas de la percepción, por lo cual, "el enlace que hace posible la unidad entre todas las percepciones y presentificaciones posicionales de un yo, lo que destacamos como tal enlace es la conexión temporal, que se funda en la esfera de la

3 Los contenidos de sensación, llamados datos hyléticos o hyle, a partir de esta obra, son los portadores de rayos de intencionalidad y cumplen la función de exhibir las determinaciones de un objeto sin ser ellos mismos partes o momentos del objeto. Husserl expresa esta fundamental diferencia cuando señala que el dato hylético que exhibe, por ejemplo, la determinación "rojo" de un objeto, es sentido, en tanto que el rojo objetivo es percibido. En otros términos, el dato de sensación es un contenido real-inmanente de la conciencia, un componente noético, como la aprehensión, mientras que la coloración del objeto exhibida por medio de él es trascendente, es decir, noemática. Por eso mismo afirma que no hay diferencia entre el sentir y lo sentido: solo serían distinguibles si entre ellos mediara una relación intencional, como ocurre en el caso del objeto, que es percibido como correlato (noemático) de las operaciones constituyentes (noéticas) (Rabanaque, 1993, pp. 8, 9). pasividad y ello implica, en la sensibilidad" (Husserl, 1980, p. 181).

En particular, el tiempo cronológico posiciona el cuerpo, lo ubica en una determinada época y en este orden da lugar a un entorno específico. Hace posible percibir un mundo de juego, y de videojuego en especial, lo cual no sería posible en la Edad Media, por ejemplo, o en la Antigüedad, al menos, no como lo conocemos en la actualidad. Un mundo de videojuego donde el sentido se vincula con las posibilidades relacionadas a la programación informática de los ordenadores. Aquí, en el videojuego el tiempo adquiere una particular forma de situar que desde

el tiempo del relato debe ser un tiempo inscrito en el relato y no fuera de él, en estricta tradición narratológica. [...] Las paradojas temporales pueden evitarse sustituyendo las anacronías por lugares narrativos del viaje temporal. Un problema temporal tiene, en el videojuego, una solución espacial. (Anyó, 2011, p. 506).

En el videojuego, el tiempo es resuelto a partir de la espacialidad, se hace posible que el entorno de juego, como espacio, juegue con el tiempo generando una narración ubicada en el siglo XII, con el videojuego Assassin's Creed o, en el espacio exterior como en Halo. Esta posibilidad del videojuego de hacer del tiempo un manejo espacial y en este sentido contribuir a la construcción ficticia de la narración que tiene lugar desde el personaje o avatar del jugador entra en resonancia con su posición temporal, quien desde un mundo del siglo XXI interactúa y transita hacia la ficción de mundos de épocas pasadas, presentes y futuras.

El jugador como sujeto sensible frente a la pantalla y su mundo circundante objetivo físico son puestos a prueba desde el videojuego, en cuanto se problematiza la posición temporal planteada ahora desde un mundo de ficción, desde características en que la vivencia y la percepción construyen otras formas de relación con la realidad, mundos donde el sentido se vincula con posibilidades propias de la programación informática de mundos posibles en los que,

sus limitaciones son las impuestas por los sistemas de reglas, no por la realidad física o consideraciones morales. El tiempo podría ir hacia atrás, la gente podría tener poderes sobrehumanos, todo es posible. Lo que se requiere es la consistencia. (Turkle, 2005, p. 78). 
Esta consistencia conlleva a posicionamientos, cuerpos y tiempos en los que "hay otro mundo donde todo es posible, pero en el que nada es arbitrario. [...] como la ciencia ficción" (Turkle, 2005, p. 80). Un mundo donde las cinestesias del cuerpo físico se vinculan al personaje a través de los controles, la pantalla y la interfaz donde la vista y el tacto, en particular, se ubican y conforman un espacio para la experiencia de juego, donde la sensibilidad configura el escenario perceptivo de la narración. Una sensibilidad que se transforma en movimiento a partir de un avatar por los hilos narrativos posibles de ser interactuados a través de la interfaz. "La interfaz es la forma cultural típica de los medios digitales y particularmente de los videojuegos. Es a través de la interfaz que se conecta el mundo del usuario con el mundo del personaje" (Anyó, 2011, p. 505).

En el videojuego, a diferencia del juego tradicional en el que el jugador interactúa de forma directa con los objetos, espacios y jugadores, el sujeto se posiciona a través de un avatar que hace las veces de jugador in situ, en la interfaz puesta en pantalla; es a partir de este avatar que se hila la trama del videojuego, que a manera de personaje es ejecutado por quien está frente a la pantalla. De esta forma:

[...] el avatar o imagen virtual de un jugador no es una representación del sujeto que juega, sino que es una simulación, un desdoblamiento, y, en últimas, la emergencia de un cierto tipo de sujeto virtual, que aunque tenga semejanzas con el jugador tangible, es distinto, y hay que observarlo y comprenderlo de una manera independiente. (Cabra, 2011, p. 91).

Fenomenológicamente, el avatar se manifiesta, se configura en un cuerpo digital otro, de quien lo crea, moviliza y/o lo actúa, lo cual problematiza la creación de sentido, según sea dada la realidad propuesta por el videojuego, de su trama al ser jugada desde el sujeto frente a la pantalla. Respecto a este avatar como otro de quien está frente a la pantalla, es necesario observar que,

[...] para poder imitar al otro buscando tener vivencias semejantes a las suyas es necesario primero constituir su vida como vida diferente de la mía, aunque esta vida ajena se mantenga inaccesible en su contenido concreto. [...] vivirla tal y como la han vivido los otros es una imposibilidad esencial entre otras razones porque solo nos es accesible en el marco de nuestra propia vida. En cambio, lo que sí podemos comprender e incluso reproducir de la vida de los otros son los tipos generales que se sostienen en esta vida habitual. (Marín, 2012, pp. 601, 602).

El otro como avatar desde la fenomenología, implica otro según la trama del videojuego, no obstante, la carga subjetiva la lleva el jugador que se ubica frente a la pantalla. Este intenta la vivencia del personaje que a su vez hace parte de un autor escenificado en la forma de videojuego. Quizás el videojuego haga las veces de escenario a través del cual el jugador se desdobla, se hace avatar, constituyendo jugar como una reproducción de habitualidades referidas a la vida singular del autor puesto en la pantalla y de quienes lo hicieron posible como videojuego. El avatar como un otro configura otro escenario también, que requiere que el jugador se ponga en el lugar del personaje-avatar para desarrollar su juego. El jugador frente a la pantalla intenta ponerse en el lugar de su personaje, lo cual se traduce como intentar ponerse en el puesto del avatar. De esta forma, es preciso indicar que las sensaciones del jugador se problematizan ya que,

tampoco el cuerpo es solamente aprehendido como dependiente respecto del estrato de sensaciones primario, su estrato propiamente localizado, sino también respecto de los campos de sensaciones y grupos de sensaciones que se le adjuntan mediatamente y no están propiamente localizados, como por ejemplo respecto del campo visual. (Husserl, 2005, p. 196).

Este aspecto relativo a la sensación resulta relevante en cuanto "el mismo cuerpo que me sirve como medio de toda percepción me estorba en la percepción de sí mismo y es una cosa constituida de modo curiosamente imperfecto" (Husserl, 2005, p. 199). En el videojuego es posible ver al personaje avatar ya que se constituye como un otro animado, graficado, ya sea en dos o tres dimensiones. Y este ver se problematiza cuando el juego representa y anima solo los brazos y manos junto con el arma en pantalla (Halo) la visión del jugador resulta en la visión del avatar y así también en sus manos, lo que conlleva a vivenciar y percibir de forma diferente la trama propuesta y, en consecuencia, a involucrar de diferentes maneras e intensidades al jugador en el juego mismo. 
Más aún, no será igual la sensación de ver frente a un televisor, o frente a la pantalla de un móvil, por lo que el dispositivo de juego afecta también su vivencia, su percepción, la inmersión del jugador en el juego. La visión tiene un papel fundamental en la experiencia del juego, ya que su ausencia anula o problematiza la posibilidad de juego, al menos desde las habitualidades relacionadas con el videojuego.

En este orden, las sensaciones propias, las del jugador, para lo cual hay unas limitaciones y posibilidades corporales, entran en sintonía, se conjugan con las limitaciones y posibilidades impuestas por la pantalla y los requerimientos de hardware. El cuerpo y sus sensaciones articulan y orientan una pericia en el manejo de los diferentes accesorios y posibilidades de acción propios de la propuesta narrativa del juego. De acuerdo con Turkle (2005):

Para un maestro del videojuego, el juego consciente no es suficiente. Usted tiene que "pensar con los dedos". [...] Un atleta piensa con el cuerpo. Usted siente los esquís como parte de usted, usted sabe su relación con el espacio circundante, objetos y obstáculos en el camino directo que se siente su cuerpo en el espacio. Lo llaman "memoria muscular", lo llaman "flujo", lo llaman "confiar en sus instintos", la experiencia de sentir una continuidad entre la mente y el cuerpo es parte del juego interior de cualquier deporte bien jugado. Los videojugadores expertos experimentan esta inmediatez de saber su juego con más que con su cabeza, y la experiencia es una emoción estimulante. (Turkle, 2005, p, 84) (texto original en inglés, traducción propia).

Entonces, el avatar como otro personaje del jugador referencia o funciona como un otro a quien intento colocarle mis percepciones, mi cuerpo, mis sensaciones, pero que no obstante es otro. Así, el videojuego constituye una subjetividad que desde la relación entre cuerpo- máquina-interfaz-avatar, "se asoma" a otro mundo, donde el jugador frente a la pantalla se moviliza con su cuerpo en pos de movilizar a ese otro, a ese personaje digital. Se trata precisamente de la constitución de subjetividad donde, de manera inicial, puede pensarse que se trata una transición que va del cuerpo físico a un cuerpo digital o avatar. Husserl (2005) comenta que "lo subjetivo es frente a la realidad una irrealidad. Realidad e irrealidad se copertenecen esencialmente en la forma de realidad y subjetividad, ambas excluyéndose y por otra parte ambas, como hemos dicho, exigiéndose esencialmente" (p. 97).

En el videojuego se puede decir que el otro como avatar se constituye en otro, o el muñeco, como lo llaman algunos jugadores, del cual solo conozco su aspecto, y así se constituye como irreal en términos de personaje de la narración, pero deberé reconocerlo a través de la trama narrativa en la que me comprometa.

En mi relación con el otro, ese otro como cuerpo físico para el cual no me es posible ver sus vivencias, su subjetividad, esta se constituye para mí en algo irreal. El videojuego pone de manifiesto una interacción sujeto-máquina donde la constitución de la subjetividad aparece como irreal para la percepción, en cuanto el avatar se orienta por el tejido narrativo o lo construye, es posible pensar la subjetividad en términos de la narración en el videojuego. Cuerpo-máquina-interfaz constituyen una unidad que hace posible configurar la experiencia de juego. Las sensaciones del cuerpo le permiten coincidir con el avatar-personaje en el desarrollo de la trama. Obando y González (2010), afirman que,

en el videojuego, los contenidos y secuencias que se prevén en el diseño lógico no son los que el videojugador interpreta haciéndose a una comprensión que pasa por el cuerpo, la palabra y la emoción. La resolución dinámica de un videojuego contrasta con lo que podría esperarse de una resolución lógica y mentalista del mismo. (p. 15).

Entonces, la emoción y la palabra se suman a los aspectos mencionados que con respecto al videojuego configuran la base para pensar los procesos de constitución de subjetividad. De manera que las diferentes cinestesias tienen lugar en la percepción del mundo y tienen como eje articulador el cuerpo,

Estas cinestesias de los órganos transcurren en el yo hago y están sujetas a mi yo puedo; además, al poner en juego esas cinestesias, yo puedo empujar, impeler, etc., y, en virtud de ello, obrar corporalmente, de modo inmediato y luego mediato. Por mi actividad perceptiva experimento (o puedo experimentar) toda la naturaleza, inclusive mi propia corporalidad orgánica, que en tal proceso está, por tanto, referida a sí misma. Esto es posible por el hecho de que yo siempre puedo percibir una mano mediante la otra, un ojo mediante una mano, etc.; así, pues, el órgano funcionante tiene que convertirse en objeto y el objeto en órgano funcionante. (Husserl, 1979, p. 160). 
Es decir, desde la síntesis pasiva el cuerpo hace las veces de primer elemento constitutivo de la subjetividad en cuanto ejecutor primero y perceptor del mundo, de la acción, lugar de memoria experiencial donde la acción es actualizada intuitivamente. Marín (2012) afirma que,

estamos habituados a nuestro cuerpo - tal y como lo hemos usado y constituido-y que algunas habitualidades se expresan, en efecto, a través del cuerpo, como gestos. [...] para Husserl lo habitual tiene que ver con la preservación de la identidad del yo. Todos los yoes tienen propiedades permanentes, habitualidades. (p. 601).

El yo puedo en tanto movimiento y percepción constituye la experiencia, crea espacios para performativizarla, recrearla, rehacerla, hacerla cuerpo, espacio para otras formas de decir y habitar el espacio. Desde la formación y en particular desde la experiencia de juego, este yo puedo se matiza ya que,

El otro, según su sentido constituido remite a mí mismo. El otro es reflejo de mí mismo y, sin embargo, no es estrictamente reflejo; [...] no solo teniendo en cuenta sus vivencias, sino también sus unidades de validez concretamente inseparables de él, tiene que plantearse necesariamente la cuestión acerca de cómo mi ego, dentro de su propiedad, puede constituir justamente lo extraño bajo el título "experiencia del extraño" - es decir, con un sentido que excluye lo constituido del contenido concreto del yo mismo concreto constituyente del sentido, en cierto modo como un analogon-. (Husserl, 1979, pp. 156, 157).

Se puede indicar que la constitución subjetiva tiene como referente al otro, me constituyo con respecto al otro, pero también es posible decir que el otro se constituye con respecto a mí, no obstante, no soy el otro y el otro no soy yo, pero, gracias a ese otro es posible mi existencia. Desde el videojuego como experiencia subjetiva constituyente, el otro profesor, jugador, estudiante, padre, el otro, en tanto compartimos el mundo, sus sentidos, sus tipificaciones, habitualidades, y yo estamos interrelacionados, nos estamos constituyendo, él sabe de mí como videojugador, yo de él como otro.

Resignificar al otro y a mí mismo, en cuanto la pregunta: ¿qué experiencia de percepción, de cuerpo, configura la experiencia de videojuego? Y, desde aquí, ¿cómo se configura el otro? Esto teniendo presente que Turkle (2005), a propósito de los jóvenes y niños frente al ordenador (máquina), comenta que:

el estilo de "control directo" no depende necesariamente de contacto físico con el hardware. Cuando se programa en la máquina o en lenguaje ensamblador, se está escribiendo en un teclado. El sentido de la relación física depende del contacto simbólico. (p. 176)

En términos de pasividad, la relación sujeto-máquina-software implica asociaciones típicas de hábitos, de emoción, de movimiento, de cuerpos en los que reconozco al otro jugador, otro de acuerdo con el mundo en que nos inscribimos y que inscribimos.

Dispuestas así las cosas, sucede que el videojuego, como se había mencionado, conlleva una transgresión de las leyes físicas, siendo válidas ahora las leyes de la programación informática, donde el avatar como imagen simula al jugador

Esta imagen virtual es la simulación del cuerpo del jugador, es la posibilidad de participación en los mundos posibles del videojuego. Y es aquí donde aparece otra de las características propias del videojuego, y es el hecho de que se configura una relación particular entre el mundo del juego y el cuerpo del jugador. [...] el videojuego se distingue de otros tipos de juego, en la medida en que transgrede y recompone las fronteras establecidas entre lo imaginario y lo real, entre lo real y lo virtual. (Cabra, 2011, pp. 86, 87).

Así, el videojuego manifiesta no solo un juego con los objetos y personajes de la narración sino que se juega también con la imagen propia, se transgrede la realidad física, lo que conlleva a múltiples inflexiones que van desde lo real hasta la ficción; que transponen la experiencia y así un juego subjetivo desde el cuerpo y el ser en situación donde la conexión cuerpo-máquina-interfaz hace un trasbordo en la regla y en la realidad misma. El cuerpo es "constituyente, en cuanto instancia de la subjetividad que da cuenta de las cinestesias, y constituido, en la medida que es objetivado como un cuerpo físico (Körper) junto con otros cuerpos físicos" (Rabanaque, 1993, pp. 18, 19). En síntesis pasiva las cinestesias del cuerpo configuran modos de estar y videojugar, formas de relación con el juego y con los otros, asimismo, mantiene potencialmente alternativas para orientar la acción, 
las cuales actualiza en los diferentes momentos de juego e interacción.

Pensar la formación en el sentido de reivindicar elementos como el cuerpo, la experiencia que en relación con el mundo circundante del sujeto hacen posible formas de entender al otro, en tanto sus hábitos y como se expresa en su videojugar. En este orden de ideas, el maestro no solo enseña desde las intencionalidades de la clase, sino que, desde su cuerpo y la escenificación que hace de sus cinestesias en conjunción con su palabra, su emoción y desde el marco de su espacio de conocimiento, pone en movimiento formas de constitución experiencial en los otros, contribuye en la constitución de la realidad, del sentido que los otros dan a la realidad.

Soy responsable de la forma en que mis acciones y tendencias se convierten en parte de las experiencias de otras personas y dan forma a la manera en que tengan sentido del mundo. Ya sea que lo pretenda o no, porque yo no solo estoy constituido por el mundo, sino que también sirvo para ayudar a constituir el mundo. (De Roo, 2013, p. 85).

Es posible afirmar que no solo el videojuego constituye la experiencia y sentido de los otros, nosotros, como maestros y maestras estamos también siendo constituidos por esas prácticas de juego, aunque no participemos de forma directa de tal experiencia. El videojuego no solo constituye un objeto más, contribuye a la conformación subjetiva. Como objeto en el que el cuerpo es problematizado, para quien lo juega, se hacen posible otras formas de relación con el mundo. Tanto para los actuales estudiantes como para los maestros, el juego en general y el videojuego en particular, es o ha sido parte de su experiencia, de su estar en el mundo. Por lo mismo constituye un espacio desde el cual se ha configurado el sentido que le damos a la vida. Así, "el significado no se añade al mundo después de los hechos, sino más bien el mundo que me encuentro es siempre un mundo significativo" (De Roo, 2013, p. 81), en tanto, compartimos sus significados.

El "tiempo objetivo, ser objetivo y todas las determinaciones del ente como objetivas no se refieren a un ser solo para mí, sino también para los demás" (Husserl, 1980, p. 174). Lo objetivo aquí en tanto real o ficcional afecta a quienes hacen parte circundante y a quienes participan de la experiencia. En consecuencia, la experiencia de juego no se reduce a un solo videojugador, tampoco a un solo lugar; en la escuela y en otros múltiples espacios tiene lugar una corporalidad que está videojugando frente a alguna pantalla, así, la aprehensión del videojuego constituye una experiencia abierta a la constitución de sentido subjetivo.

Desde la formación, la síntesis pasiva hace posible una relación con el mundo y con los otros, donde el tránsito entre la vivencia y la percepción moviliza formas habituales de habitar, descentrarse y oscilar entre unas vivencias de juego automáticas, pasivas, a otras donde el otro, como otro, con vivencias diferentes, permite percepciones a otros movimientos del cuerpo y de las pasividades.

\section{REFERENCIAS}

Anyó, S. L. (2011). El meu videojoc, la nostra narració. Els relats de la identitat. Universidad Àrea de Cinema i Televisió. Departament de Comunicació Facultat de Comunicació Blanquerna. Universitat Ramon Llull. Barcelona, España.

Cabra, N. A. (2011). Entre el fantasma, el avatar y otras mutaciones de la imagen. Revista Nómadas, 35, 81, 91.

Escudero, J. A. (2013). La actualidad de la fenomenología husserliana: superación de viejos tópicos y apertura de nuevos campos de exploración. Eidos (18), 12-45. Recuperado de http://www.scielo.org.co/pdf/eidos/n18/n18a02.pdf

De Roo, N. (2013). Phenomenological insights into oppression: Passive synthesis and personal responsibility. Janus Head, 13(2), 81, 99.

De los Reyes, M. I. (2013). La problemática de la normalidad en la fenomenología trascendental. Tesis doctoral. Universidad Complutense de Madrid. Madrid, España.

Dreyfus, H. L. y Dreyfus, S. E. (1983). De Sócrates a los sistemas expertos: los límites y peligros de la racionalidad calculante (Trad. R. Rizo-Patrón). Folios,12, 2000, 1-10.

Husserl, E. (2005). Ideas relativas a una fenomenología pura y una filosofía fenomenológica: libro segundo: investigaciones fenomenológicas sobre la constitución, (Trad. A. Zirión Quijano). México: UNAM, Instituto de Investigaciones Filosóficas.

Husserl, E. (2001). Analyses concerning passive and active synthesis. Lectures on transcendental logic. En E. Husserl. Collected Works Editor: R. Bernet, vol. LX. Traducido por Anthony J. Steinbock. Recuperado de https:// richardfong.files.wordpress.com/2011/02/husserl-edmund-analyses-concerning-passive-and-active-synthesis-kluwer-academic-publishers-2001.pdf 
Husserl, E. (1980). Experiencia y juicio. Investigaciones acerca de la genealogía de la lógica. Redacción y edición de Ludwig Landgrebe. Con un epílogo de Lothar Eley. Traducción: Jas Reuter. Revisión de Bernabé Navarro. México: Universidad Nacional Autónoma de México.

Husserl, E. (1979). Meditaciones cartesianas. Introduccion, traducción y notas por Mario A. Presas. Buenos Aires: Ediciones Paulinas; Universidad de Buenos Aires.

Marín, A. E. I. (2012). El carácter expresivo del cuerpo y lo inaccesible de lo ajeno. Acta Fenomenológica Latinoamericana, (IV) pp. 591-611. Lima: Pontificia Universidad Católica del Perú. Recuperado de http://www. clafen.org/AFL/V4/591-611_ART_Marin.pdf

Merleau-Ponty, M. (1993). Fenomenología de la percepción. Barcelona: Planeta de Agostini. Recuperado de https://filosinsentido.files.wordpress.com/2013/07/ merleau-ponty-maurice-fenomenologia-de-la-percepcion.pdf

Obando, O. L. y González, J. (2010). Pensar con los pies. Dinámicas elocutivas, corporales y emocionales en la práctica de videojuego. Cali: Universidad del Valle.

Rabanaque, L. R. (1993). Campo de trasfondo y dato hyelético. Agora, 12(2), 7, 21.

Turkle, S. (2005). The second self: Computers and the human spirit (20 $0^{\text {th }}$ edition). Cambridge, Londres: $20^{\text {th }}$ The MIT Press

Turkle, S. (1997). La vida en pantalla. La construcción de la identidad en la era de internet, (Traducción de Laura Trafí). Barcelona: Ediciones Paidós Ibérica. 